\title{
Retrieval of methane source strengths in Europe using a simple modeling approach to assess the potential of spaceborne lidar observations
}

\author{
C. Weaver ${ }^{1,2,3}$, C. Kiemle ${ }^{3}$, S. R. Kawa ${ }^{1}$, T. Aalto ${ }^{4}$, J. Necki ${ }^{5}$, M. Steinbacher ${ }^{6}$, J. Arduini ${ }^{7}$, F. Apadula ${ }^{8}$, H. Berkhout ${ }^{9}$, \\ and J. Hatakka ${ }^{4}$ \\ ${ }^{1}$ NASA Goddard Space Flight Center, Greenbelt, MD 20771, USA \\ ${ }^{2}$ Earth System Science Interdisciplinary Center (ESSIC), University of Maryland, College Park, MD 20740, USA \\ ${ }^{3}$ Deutsches Zentrum für Luft- und Raumfahrt, Oberpfaffenhofen, Germany \\ ${ }^{4}$ Finnish Meteorological Institute, Helsinki, Finland \\ ${ }^{5}$ AGH University of Science and Technology, Krakow, Poland \\ ${ }^{6}$ Empa, Swiss Federal Laboratories for Materials Science and Technology, Laboratory for Air Pollution/Environmental \\ Technology, Dübendorf, Switzerland \\ ${ }^{7}$ University of Urbino, Urbino, Italy \\ ${ }^{8}$ Research on Energy Systems, Environment and Sustainable Development Department, Milano, Italy \\ ${ }^{9}$ RIVM, Centre for Environmental Monitoring, Bilthoven, the Netherlands
}

Correspondence to: C. Weaver (clark.j.weaver@nasa.gov)

Received: 30 May 2013 - Published in Atmos. Chem. Phys. Discuss.: 24 July 2013

Revised: 14 November 2013 - Accepted: 14 January 2014 - Published: 14 March 2014

\begin{abstract}
We investigate the sensitivity of future spaceborne lidar measurements to changes in surface methane emissions. We use surface methane observations from nine European ground stations and a Lagrangian transport model to infer surface methane emissions for 2010. Our inversion shows the strongest emissions from the Netherlands, the coal mines in Upper Silesia, Poland, and wetlands in southern Finland. The simulated methane surface concentrations capture at least half of the daily variability in the observations, suggesting that the transport model is correctly simulating the regional transport pathways over Europe. With this tool we can test whether proposed methane lidar instruments will be sensitive to changes in surface emissions. We show that future lidar instruments should be able to detect a $50 \%$ reduction in methane emissions from the Netherlands and Germany, at least during summer.
\end{abstract}

\section{Introduction}

Although methane $\left(\mathrm{CH}_{4}\right)$ is the second most important anthropogenic greenhouse gas, it is arguably just as important as carbon dioxide $\left(\mathrm{CO}_{2}\right)$ from a policy perspective. Several studies conclude that in order to reduce net anthropogenic radiative forcing, it costs less to cut $\mathrm{CH}_{4}$ emissions compared with $\mathrm{CO}_{2}$ emissions (Shindell et al., 2012; Delhotel et al., 2006). To monitor future $\mathrm{CH}_{4}$ emissions, policy makers and government officials will desire estimates of surface fluxes at a fine temporal and spatial resolution. Scientists also need this information to understand global and regional $\mathrm{CH}_{4}$ budgets and the physical processes that control them.

Because observed emission rates of $\mathrm{CH}_{4}$ are highly variable over small temporal and spatial scales, scientists have often resorted to a top-down approach to determine regional emissions. Total column $\mathrm{CH}_{4}$ observations from space have been used in an inversion algorithm to estimate surface emission fluxes (Bergamaschi et al., 2009; Meirink et al., 2008). Currently, the spaceborne sources for near-surface $\mathrm{CH}_{4}$ information are the Scanning Imaging Absorption Spectrometer for Atmospheric 
Chartography (SCIAMACHY) instrument on board the late ENVISAT satellite platform (Bergamaschi et al., 2007; Frankenberg et al., 2011), and more recently the Greenhouse gases Observing SATellite (GOSAT) operated by the Japan Aerospace Exploration Agency (Schepers et al., 2012). These instruments measure changes in $\mathrm{CH}_{4}$ spectral absorption from reflected near-infrared solar radiation, so they are susceptible to contamination from undetected clouds and aerosols. Too often global maps of $\mathrm{CH}_{4}$ retrievals from today's passive satellite instruments have data voids over persistent cloudy regions, even if the clouds are optically thin. They also cannot make measurements in darkness or low sunlight conditions.

There are several planned space- and aircraft-based instruments that will use laser technology to measure the total $\mathrm{CH}_{4}$ column (Riris et al., 2013; Ehret et al., 2008) and total $\mathrm{CO}_{2}$ column (Abshire et al., 2010). This approach should remedy some of the current issues concerning highlatitude coverage and scattering from clouds and aerosols. Indeed, a recent aircraft demonstration campaign to test the feasibility of lasers to measure $\mathrm{CO}_{2}$ has successfully retrieved $\mathrm{CO}_{2}$ concentrations in thin cloud conditions (A. Ramanathan, personal communication, 2013; Abshire et al., 2013). In the frame of a German-French climate monitoring initiative, DLR (Deutsches Zentrum für Luft- und Raumfahrt) and CNES (Centre National d'Etudes Spatiales) proposed a MEthane Remote LIdar MissioN (MERLIN) on a small polar orbiting satellite. The DLR Institute of Atmospheric Physics is also developing an airborne lidar system for demonstration and satellite validation purposes. Performance simulations have shown the basic ability of such active remote sensing systems in improving the accuracy of global methane observations (Kiemle et al., 2011; Stephan et al., 2011).

The question remains whether these new instruments will be able to detect changes in surface $\mathrm{CH}_{4}$ emissions that occur at the state, nation or continent spatial scale. These changes may arise from policies that hopefully reduce anthropogenic emissions or from natural processes, which include climate feedback effects on permafrost soils, ocean hydrate sediments, and wetlands, in regions that are often difficult to access. This study's approach is to first build a retrieval algorithm that estimates $\mathrm{CH}_{4}$ emissions using the FLEXPART Lagrangian transport model constrained by hourly $\mathrm{CH}_{4}$ surface observations. Then we evaluate our emission estimates with existing emission inventories to ensure that our emissions are realistic and the method is sound. The second part of this study applies this tool to remote sensing. We build an algorithm that inverts surface emissions from total column measurements. With this tool we test whether the proposed satellite instruments will be able to detect perturbations in column $\mathrm{CH}_{4}$ based on the precision of future spaceborne instruments.

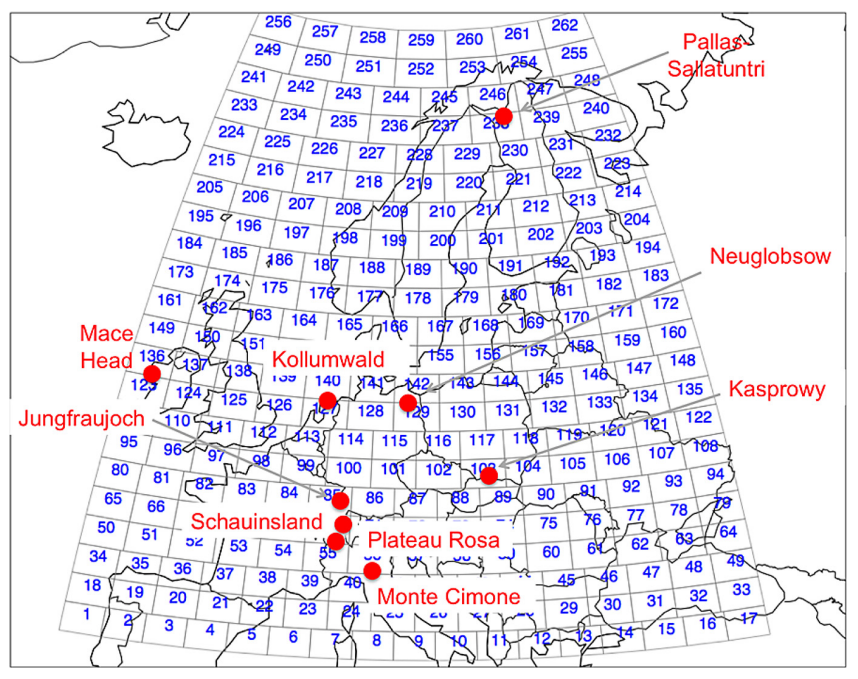

Fig. 1. The 262 tiles used in this study are $1.5^{\circ}$ in latitude, and 1.5 to $7^{\circ}$ in longitude, from south to north, in order to obtain a constant area of approximately $7000 \mathrm{~km}^{2}$.

\section{Forward models}

The two variations of the forward model used in this study start with gridded fields of $\mathrm{CH}_{4}$ surface emissions and output either (1) concentrations at the ground, simulating observations from monitoring stations or (2) total column amounts, simulating observations from satellite. The driver for both is FLEXPART - a 3-dimensional particle dispersion model developed at the Norwegian Institute for Air Research (Stohl et al., 2005). Our approach is to divide northern Europe into 262 tiles (Fig. 1) and assume a uniform emission flux from these tile. The FLEXPART model is run independently for each tile using the NOAA Global Forecast System (GFS) meteorology fields at $3 \mathrm{hr}$ time and $0.5^{\circ}$ resolution. The GFS uses 64 vertical sigma-pressure hybrid layers. The FLEXPART model actually transports the $\mathrm{CH}_{4}$ as particles that have a lifetime of 20 days. We understand that $\mathrm{CH}_{4}$ 's actual lifetime is on the order of twelve years, but uncertainties of the FLEXPART model grow so that after 20 days the results are unreliable. We are implicitly assuming that after 20 days the $\mathrm{CH}_{4}$ particles become part of a background concentration term.

For each tile we release the equivalent of $1 \mathrm{~kg}$ of $\mathrm{CH}_{4}$ at $150 \mathrm{~m}$ above ground level, assume a climatological $\mathrm{OH}$ field, and an $\mathrm{OH}$ reaction rate that varies with temperature $\left(3.5 \times 10^{-15} \mathrm{~cm}^{3} \mathrm{~s}^{-1}\right.$ at $\left.25^{\circ} \mathrm{C}\right)$. We set the FLEXPART model vertical domain to simulate concentrations from the earth surface to $400 \mathrm{hPa}$. We do not attempt to simulate stratospheric intrusions.

One forward model implementation (Fig. 2a) calculates perturbations in the surface $\mathrm{CH}_{4}$ concentration at any geographical location by adding up the contribution $\left(\mathrm{S}_{i} \cdot \mathrm{C}_{i}\right)$ from each of the 262 tiles. A background concentration (B) is also added to the perturbations. $S_{i}$ is the source strength for 


\section{a} Source Strength factor

Forward Model Surface Obs

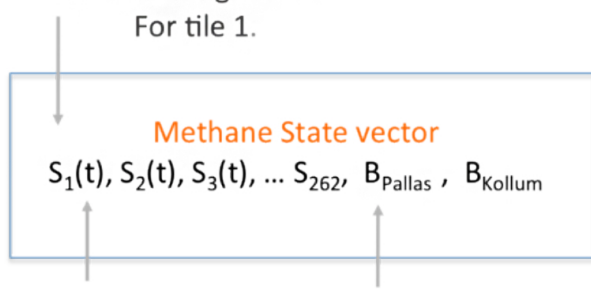

45 day time resolution

Background methane Concentration at Pallas ppm

FLEXPART surface concentration

Using $1 \mathrm{~kg}$ per day source

3 hour time resolution

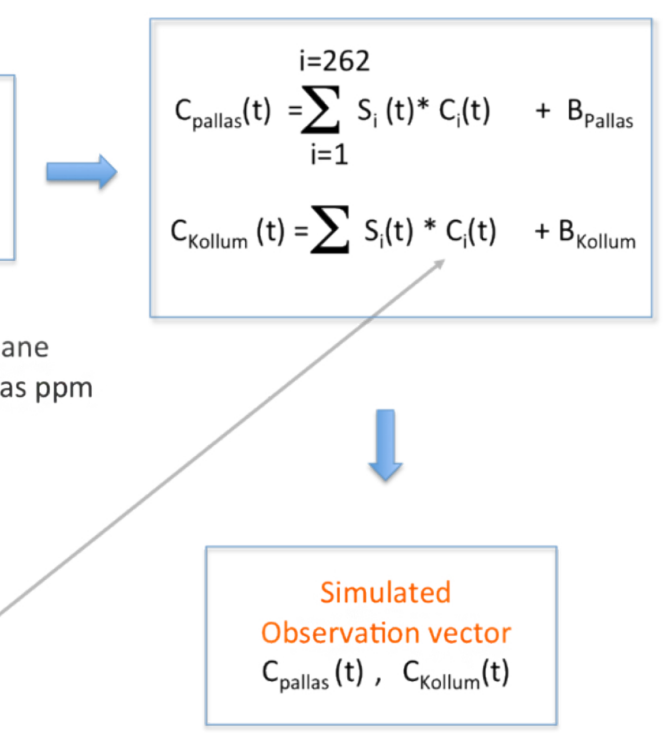

\section{b Forward Model Total Column}

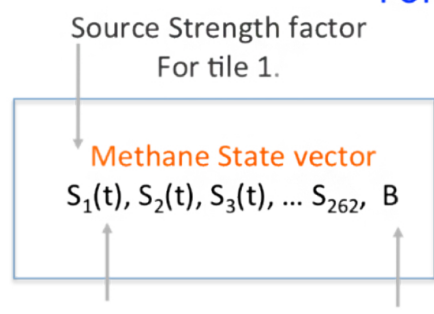

45 day time resolution
Background methane homogenous backgroud $\sim 1840 \mathrm{ppm}$

FLEXPART average column concentration Using $1 \mathrm{~kg}$ per day source 3 hour time resolution

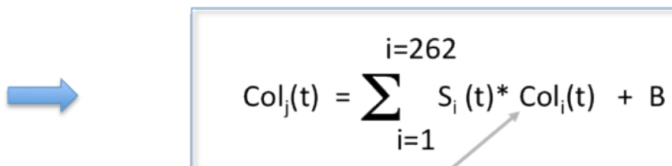

Each grid box. includes contribution of all other grid boxes so $j=1,262$

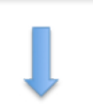

Simulated

Observation vector

$\mathrm{Col}_{\mathrm{j}}(\mathrm{t}), \mathrm{j}=1,262$

Fig. 2. (a) The forward model used to calculate surface methane concentrations. For simplicity this schematic only shows equations for two geographic locations. (b) Forward model used to calculate total column amounts.

the $\mathrm{i}^{\text {th }}$ tile and $\mathrm{C}_{i}$ is the surface concentration simulated by FLEXPART using the $1 \mathrm{~kg}$ per day source. The background value is a retrieved quantity from the retrieval algorithm.

A second forward model implementation (Fig. 2b) calculates perturbations in the total column $\mathrm{CH}_{4}$ using a similar approach. For all of our FLEXPART model runs, the simulated $\mathrm{CH}_{4}$ is able to move vertically in the atmosphere according to diabatic and convective processes captured by the GFS meteorology. While the model does not calculate an absolute column amount, it provides perturbations from an unknown total column value, which is adequate for our purposes. We output the $\mathrm{CH}_{4}$ at 20 vertical levels in the 
Table 1. Ground stations sampling hourly methane concentrations used in this study. Elevation is in meters. CRDS is Cavity Ring Down Spectrometry and GC-FID is Gas Chromatography with Flame Ionization Detector.

\begin{tabular}{llllll}
\hline Station & Lat, Lon & Elev & Method/Scale & Institution & PI \\
\hline Pallas-Sammaltunturi, Finland & $67.97,24.12$ & 560 & CRDS/ NOAA04 & FMI & Juha Hatakka, Tuula Aalto \\
Mace Head, Ireland & $53.33,-9.9$ & 5 & GCFID/NOAA04 & AGAGE & Ray Wang \\
Kollumerwaard, Netherlands & $53.33,6.28$ & 0 & GC-FID/NIST & RIVM & Hans Berkhout \\
Neuglobsow, Germany & $53.17,13.03$ & 65 & GCFID/NOAA04 & UBA & Karin Uhse \\
Kasprowy, Poland & $49.23,19.98$ & 1989 & GCFID/NOAA04 & AGH-UST & Jaroslaw Necki \\
Schauinsland, Germany & $47.92,7.92$ & 1205 & GC-FID/NOAA04 & UBA & Karin Uhse \\
Jungfraujoch, Switzerland & $46.54,7.99$ & 3580 & CRDS/NOAA04 & Empa & Martin Steinbacher \\
Plateau Rosa & $45.93,7.71$ & 3480 & GCFID/NOAA04 & RSE & Francesco Apadula \\
& & & & & Daniela Heltai \\
& & & & & Andrea Lanza \\
Monte Cimone, Italy & $44.18,10.7$ & 2165 & GCFID/NOAA04 & ISAC & Jgor Arduini \\
\hline
\end{tabular}

atmosphere (surface to $\sim 400 \mathrm{mb}$ ). Our configuration of the FLEXPART model does not loft many particles (molecules of methane) above the $400 \mathrm{hPa}$ level so its contribution to the column perturbation is insignificant. The partial column methane above $400 \mathrm{hPa}$ is spatially homogeneous and is included in the background term.

\section{Source inversions from ground-based observations}

\subsection{Retrieval algorithm}

The source retrieval algorithm estimates $\mathrm{CH}_{4}$ emissions from data sampled hourly at nine European ground stations in 2010. As shown below, the surface $\mathrm{CH}_{4}$ concentrations simulated by the transport model reproduce much of the short timescale (hourly) perturbations in the $\mathrm{CH}_{4}$ concentrations, suggesting that these fast fluctuations, rather than the slowly varying background $\mathrm{CH}_{4}$ value, provide information about the source strength over the domain.

Once the individual trajectory calculations are run for each tile, we can run the retrieval algorithm. As shown in Fig. 3, we retrieve a source strength $\left(S_{i}\right)$ for each tile and a background value (B) for each station. The retrieval algorithm adjusts the source strengths of each individual tile, until the simulated (analyzed) observations best match those observed. The background value at each station is also adjusted. A standard linear inverse method (chapter 3 of Rodgers, 2000) is used and iterated until the source strengths and background values have converged. Note that the retrieved source strengths are constant over a $45 \mathrm{~d}$ period and the retrieved background values vary linearly with time over each $45 \mathrm{~d}$ period.

The observations for this retrieval algorithm are sampled at nine European stations that continually measure surface $\mathrm{CH}_{4}$, preferably every hour. These are listed in Table 1 and further described in the Appendix. There are additional European stations that only sample weekly or monthly (labeled by "event"), but we could see no significant change in

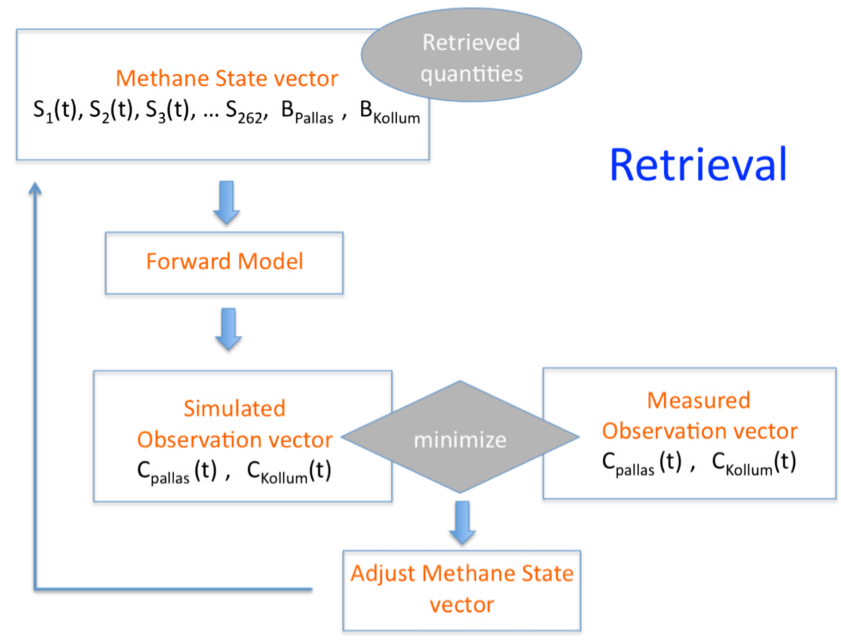

Fig. 3. Schematic of the retrieval algorithm used to obtain source strengths.

the retrieved emissions when these data sets were included. The high temporal resolution hourly observations capture information on $\mathrm{CH}_{4}$ filaments passing over a ground station, which are then deconvolved by our retrieval algorithm to yield the surface emission strengths. This interesting finding is due to the complexity of transport in association with a strong spatial heterogeneity of emissions.

Figure 4 shows the observed hourly $\mathrm{CH}_{4}$ concentrations at the nine European ground stations used for this study (black trace). The FLEXPART simulated (analyzed posterior) concentrations that best match the observations are also shown (red trace). The FLEXPART model is often able to reproduce the weekly variability and sometimes captures hourly spikes in the observations. The model performs best at the Mace Head Ireland site and the Pallas-Sammaltunturi site in northern Finland. These are remote sites situated far away from any pollution sources; moreover, Pallas is usually above the convective boundary layer. Therefore, the variability at 

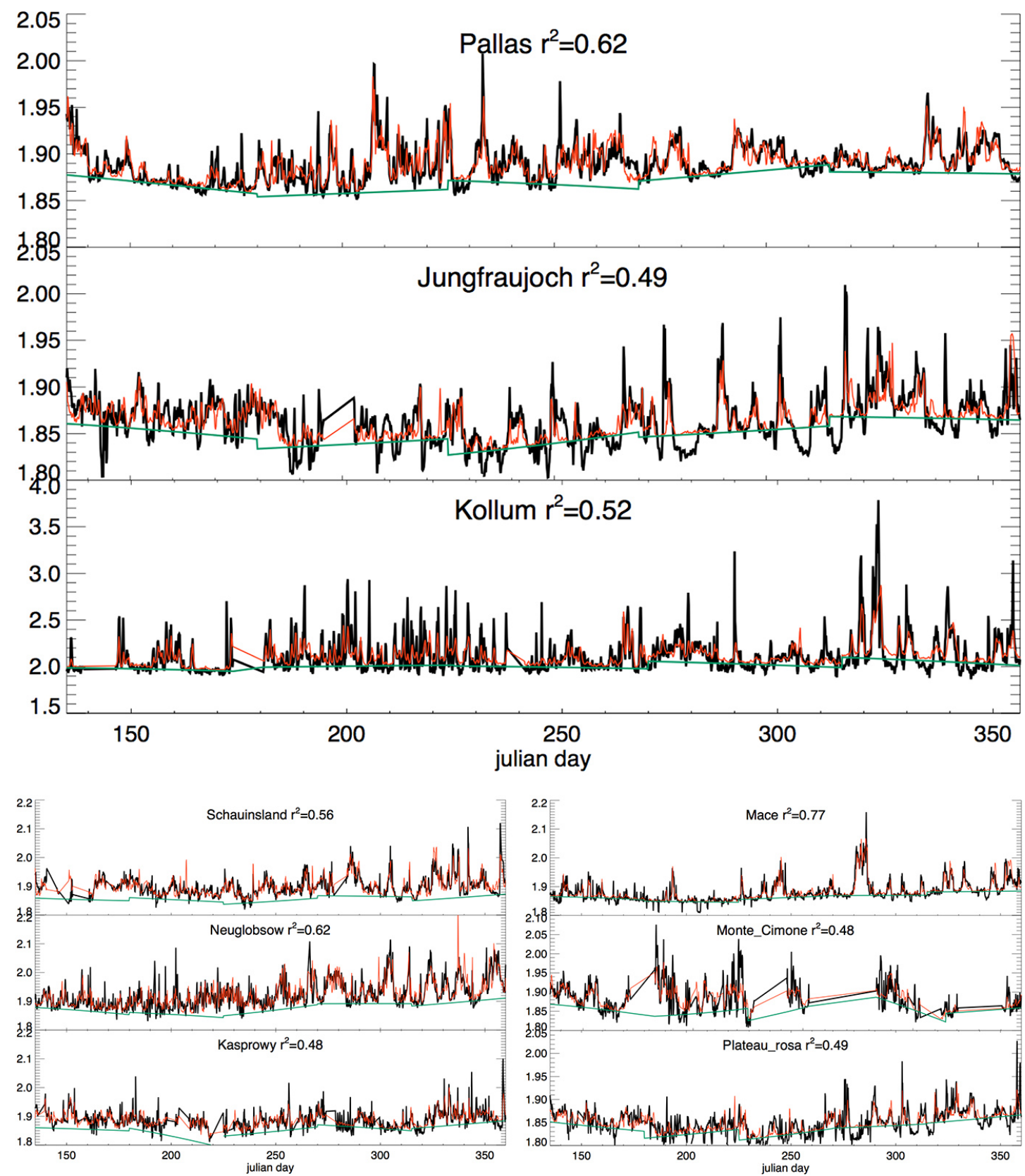

Fig. 4. Observed (black) and analyzed (red) hourly methane concentrations (ppm) at nine European locations for the year 2010. Contribution from the retrieved background concentration is shown in green. Please note that different $y$-axis scales are used for the different stations.

these sites is largely influenced by regional transport from European sources. Differences between FLEXPART simulated concentrations and the observations can be attributed to parameterization schemes employed by FLEXPART, errors in the GFS winds, the boundary conditions, the varying background concentration and/or errors in the observations themselves.

The model is unable to capture the minimum values at mountain stations: the Jungfraujoch site (elevation of $3580 \mathrm{~m}$ ), the Plateau Rosa site ( $3480 \mathrm{~m}$ ) and Monte Cimone
(2165 m), all located in the Alps, and the Kasprowy Wierch $(1989 \mathrm{~m})$ station in the Carpathian Mountains. One explanation is that the $0.5^{\circ}$ resolution NOAA GFS winds are not able to capture the actual wind patterns driven by the local complex topography. Conditions of strong upslope and downslope winds increase the influence of local $\mathrm{CH}_{4}$ sources. Indeed, at these sites the surface elevation above sea level reported by the GFS meteorological fields is much lower than the actual elevation of the station. 


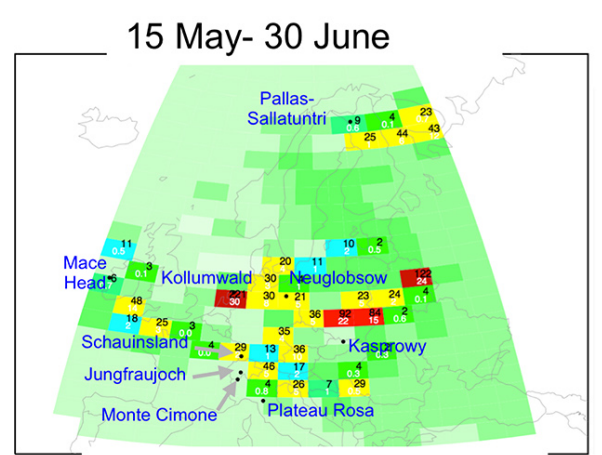

15 August - 31 September

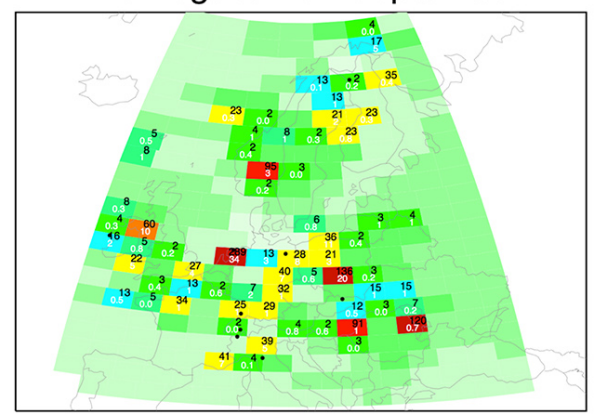

1 July - 14 August

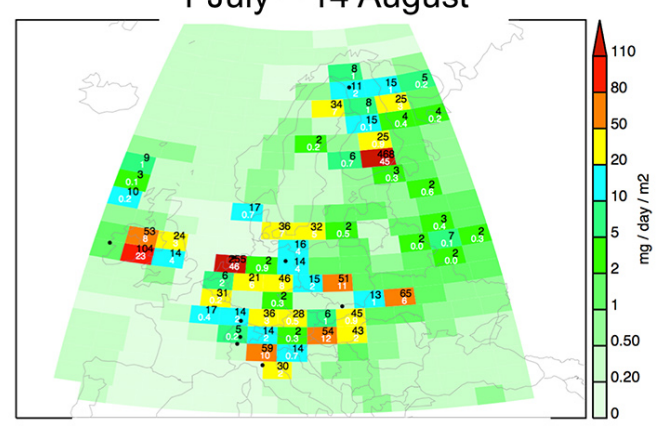

1 October - 14 November

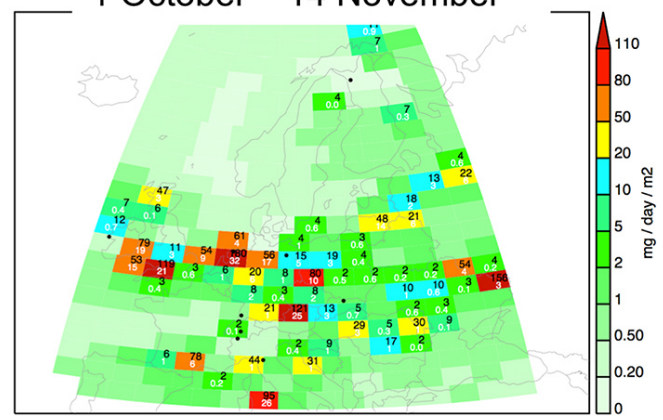

15 November - 31 December

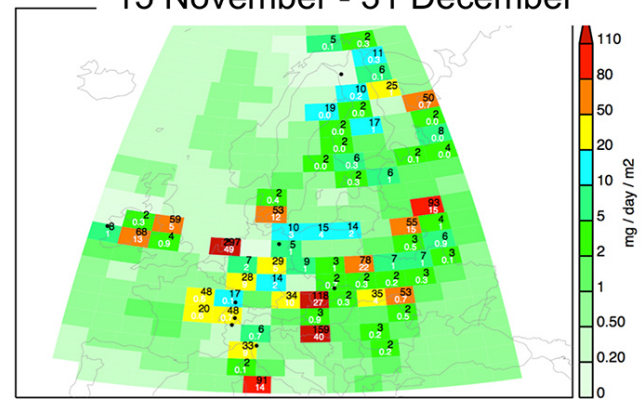

Fig. 5. Retrieved surface source strengths $\left(\mathrm{mg} \mathrm{day}^{-1} \mathrm{~m}^{-2}\right)$ for five $45 \mathrm{~d}$ periods in 2010 . Each tile with significant emission has value shown in black and estimated uncertainty in white.

Also note that while the model is able to reproduce the timing of the spikes at the Kollumerwaald site, it only simulates half the amplitude. Issues with the GFS fields and FLEXPART's simulation of boundary layer height and mixing may explain why the model captures the timing of spikes but not the amplitude. If a local source is present, a shallower nighttime boundary layer capped by an inversion will foster higher $\mathrm{CH}_{4}$ concentrations. However, a time series plot of hourly $\mathrm{CH}_{4}$ concentrations at Kollumerwaald sorted by nighttime and daytime measurements (not shown) shows that spikes are not limited to nighttime conditions. These spikes require further study.

The squared correlation coefficients between the observed and simulated concentrations range from .48 to .77 . This suggests that at least half of the variability in the observed surface concentrations can be explained by the regional transport simulated by the FLEXPART model. The remaining unexplained variability in the surface concentrations is from short temporal scale variability in the emissions strengths (we assume a constant emission over a $45 \mathrm{~d}$ time period), or weaknesses in the trajectory model, or weaknesses in the GFS meteorological fields.

In a similar study, Vermulen et al., (2006) used the FLEXPART trajectory model to simulate a time series of hourly $\mathrm{CH}_{4}$ surface concentrations at Mace Head and at the Cabauw tower in the Netherlands during 2002. They used prescribed $\mathrm{CH}_{4}$ surface fluxes from the METDAT (METhane DATabase) and the EDGAR databases. They were able to simulate $\sim 75 \%$ of the variability of the Cabauw observations and their simulation for Mace Head looks very similar to ours. Another similar study used $\mathrm{CO}_{2}$ concentration observations at three ground-based mountain stations: Plateau Rosa, Monte Cimone and Zugspitze along with the FLEXPART trajectory model to determine $\mathrm{CO}_{2}$ source and sink regions (Apadula, et al., 2003). 

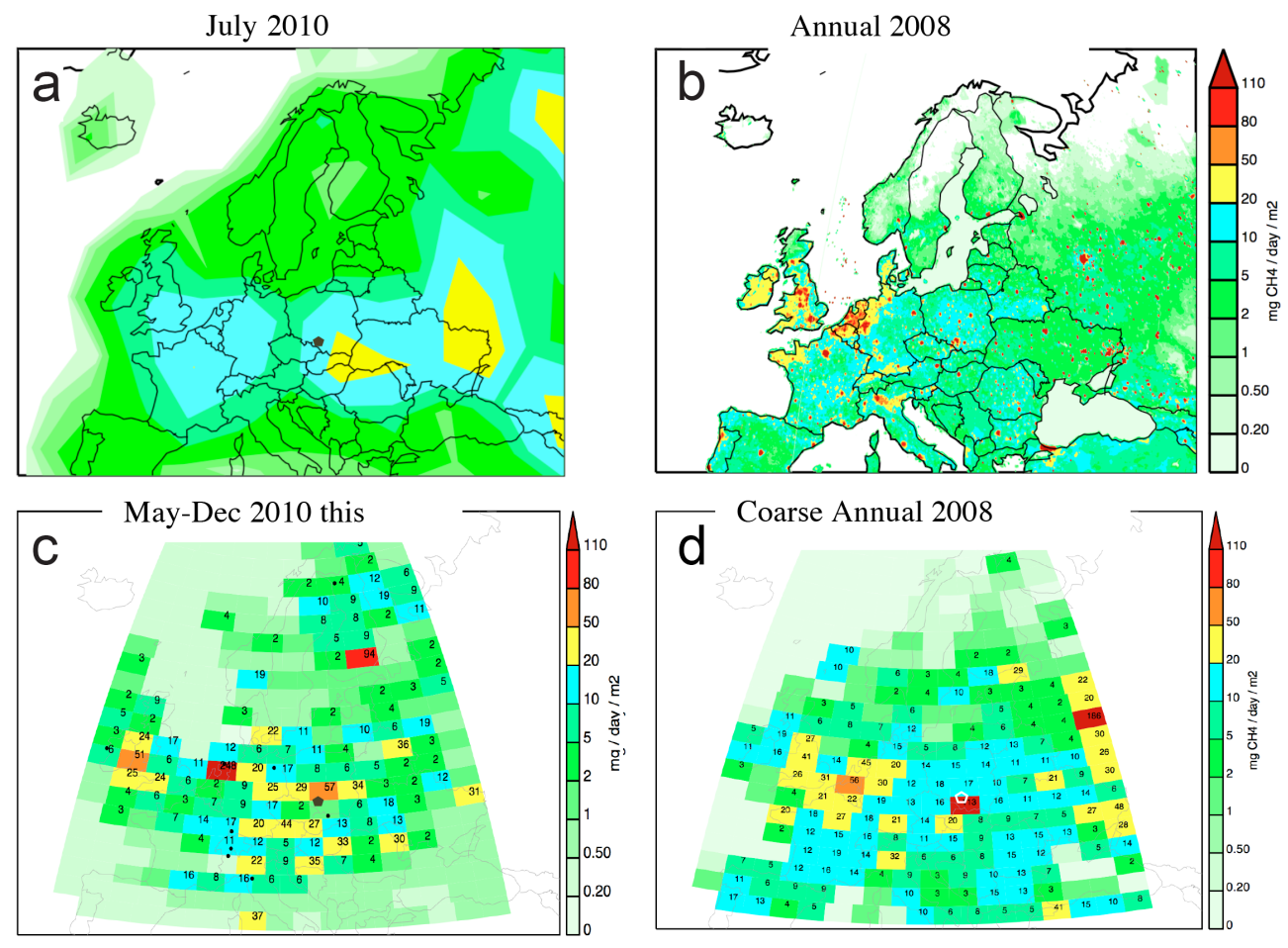

Fig. 6. (a) Monthly retrieved emission strengths from the European Monitoring Atmospheric Composition and Climate (MACC) collaborative project for July 2010. (b) Annual anthropogenic surface emissions from the Emission Database for Global Atmospheric Research (EDGAR) for 2008. (c) Average retrieved emission strengths from this study May-Dec 2010. (d) EDGAR 2008 integrated over our 262 surface tiles. (a), (c) and (d) show the upper Silesia mining district with dark pentagon. Each tile with significant emission has value shown in black

\subsection{Retrieved source strengths}

Figure 5 shows our retrieved source strengths for each tile. Note that our forward model assumes that these emissions are unchanged over a $45 \mathrm{~d}$ period. The strength values and uncertainties for tiles with significant emission are shown in black and white, respectively. The uncertainties are derived from the averaging kernels (see Rodgers 2000, chapter 4) which are a diagnostic quantity from the retrieval algorithm.

Ideally, each of the nine ground stations (Table 1) would have back trajectories transporting $\mathrm{CH}_{4}$ from each one of the 262 source tiles during a $45 \mathrm{~d}$ period. Instead, there are times when no trajectories from a source tile pass over one of the nine observing ground stations and the strength uncertainty (as determined by the averaging kernel) will be high. This was too often the case when we attempted to resolve the strengths at temporal resolutions less than 45 days; a significant number of tiles had strength uncertainties that were larger than the actual values.

Several other studies have inverted methane surface emissions using observations from ground-based monitoring stations. One study reports UK emissions using observations from the Mace Head site (Manning et al., 2011). Bergamaschi et al (2010) use data from many monitoring sites along with a nested Eulerian transport model to estimate emissions over NW Europe.

We compare our retrieved emission strengths with reanalysis fluxes from the European Monitoring Atmospheric Composition and Climate (MACC) collaborative project for 2010 (Fig. 6a). These surface fluxes are inverted from total column $\mathrm{CH}_{4}$ amounts from SCIAMACHY (Bergamaschi et al., 2009) and should include both natural and anthropogenic sources. Our retrieved surface fluxes are qualitatively consistent with the much smoother MACC reanalysis over the UK and central Europe. (Their inversion grid has a much coarser spatial resolution than ours.) However, the MACC reanalysis does not show the strong Fenno-Scandinavia emissions that we retrieve in July. This may be due to the lack of SCIAMACHY data at high latitudes.

We can also compare our surface fluxes with the Emission Database for Global Atmospheric Research (EDGAR, 2011), understanding that this data set does not include natural emissions. Figure $6 \mathrm{~b}$ shows the total anthropogenic emissions based on government and commercial statistics for 2008. The fine $0.1^{\circ}$ by $0.1^{\circ}$ spatial scale of this data set is able to resolve the strong emissions from the major metropolitan, industrial, mining and agricultural areas. To facilitate comparison we show our average retrieved emissions for May-December 

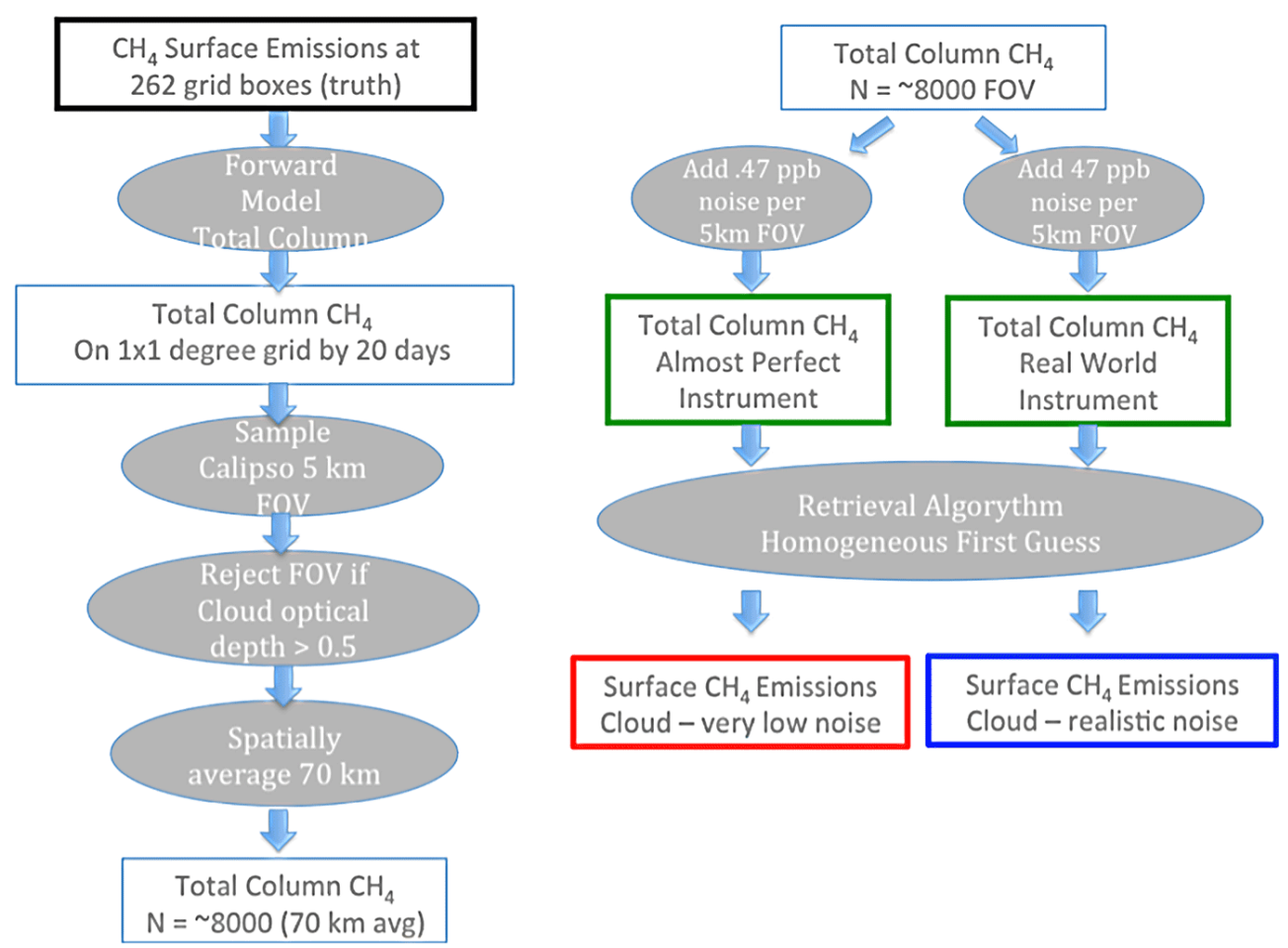

Fig. 7. Our approach to test the sensitivity of a proposed laser $\mathrm{CH}_{4}$ instrument to changes in surface emissions. First we produce values of simulated column $\mathrm{CH}_{4}$ observed by a laser instrument (green boxes) from gridded $\mathrm{CH}_{4}$ surface emissions (black box). We include the effect of a proposed satellite platform orbit, field-of-view instrument sampling, rejection of data for cloudy conditions, and instrument noise. Finally, we retrieve surface emissions (red and blue boxes) from the simulated column $\mathrm{CH}_{4}$ observations. Gridded arrays of the starting (true) and retrieved surface emissions are shown in Fig. 9. See text for further explanation.

2010 in Fig. 6c. The fine resolution EDGAR emissions are integrated over our 262 surface tiles in Fig. 6d.

Almost all of Poland's coal mining activities are concentrated in Upper Silesia (shown by the dark pentagon symbol in Fig. 6). It is one of the largest in Europe and produces almost all of Poland's coal. During the extraction process significant $\mathrm{CH}_{4}$ is released from the coal and surrounding rock. This $\mathrm{CH}_{4}$ must be quickly removed from underground mines through ventilation systems. Although some of the mines recover the $\mathrm{CH}_{4}$, a significant amount is still emitted directly into the atmosphere. The EDGAR database reports that "fugitive emissions from solid fuels" (i.e., coal production) constitute half of Poland's $\mathrm{CH}_{4}$ emissions. So the strong emission in southern Poland reported by EDGAR (113 $\mathrm{mg} \mathrm{day}^{-1} \mathrm{~m}^{-2}$, Fig. 6d) is largely from venting coal mines. Our retrieved surface fluxes also show a strong source near Upper Silesia of $57 \mathrm{mg} \mathrm{day}^{-1} \mathrm{~m}^{-2}$ shown in Fig. 6c.

The EDGAR database also shows the Netherlands as a strong source of $\mathrm{CH}_{4}$ (Fig. 6b, d). This is not associated with the tulip industry; instead, the EDGAR database cites "enteric fermentation and manure management" as the largest contributors to the Netherlands $\mathrm{CH}_{4}$ emission. Our retrievals consistently show strong emissions in this location.
The strong summer surface fluxes we retrieve over Fennoscandia (Fig. 5) are from natural sources (wetlands) so they are not reported in the EDGAR database. In the very northern parts of Fennoscandia, the natural wetlands are only moderately active during the period 15 May to 30 June; snow is melting and temperatures are cold. The active tiles to the east of Pallas are probably leaks from $\mathrm{CH}_{4}$ gas production fields located just outside the tile domain in the Russian Federation. From 1 July to 14 August, many northern tiles, especially over Finland, become active. The strongest source location $\left(468 \mathrm{mg} \mathrm{day}^{-1} \mathrm{~m}^{-2}\right.$ ) is in southern Finland (tile \#202) and is entirely dominated by lakes and wetlands. We show negligible CH4 sources during October over Fennoscandia consistent with the colder temperatures. The active tiles over Finland in December are probably anthropogenic sources but they are not yet understood.

\section{Application to remote sensing}

Remote sensing laser instruments designed to measure $\mathrm{CH}_{4}$ from air and spaceborne platforms are being developed in Europe and the United States. The spaceborne and aircraft version of the MERLIN (DLR/CNES) instrument is expected to have a precision of $\sim 18 \mathrm{ppb}$ over $50 \mathrm{~km}$ spatial averaging 

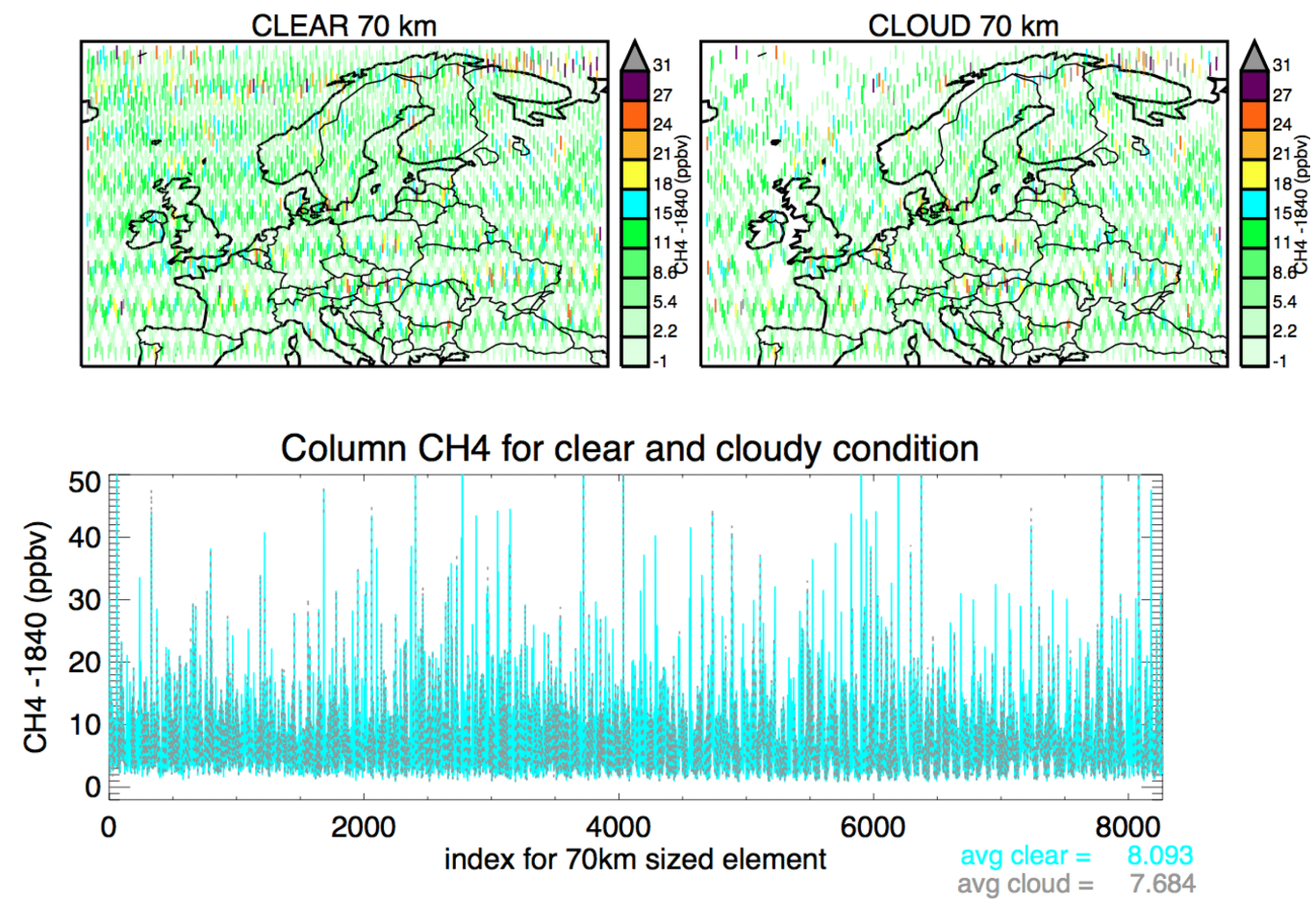

Fig. 8. (a) Simulated total column $\mathrm{CH}_{4}$ values observed by a proposed laser instrument averaged to a $70 \mathrm{~km}$ spatial resolution, assuming clear sky conditions. (b) Same as (a) but rejecting $\mathrm{CH}_{4}$ values co-located with CALIPSO-observed cloud optical depths greater than 0.5. (c) Same as (a) and (b) except plotted by sample number index.

(Kiemle et al., 2011). The Methane Sounder, being developed at NASA Goddard Space Flight Center, was tested on the NASA DC-8 in the summer of 2011 (Riris et al., 2012). While this is a breadboard instrument, only designed to demonstrate the use of laser technology, its precision is $\sim 50 \mathrm{ppb}$. The expected precision from the mature instrument design is $\sim 14 \mathrm{ppb}$. But will these new instruments (MERLIN and NASA Methane Sounder) be able to detect changes in the current emission rates?

To study this, we need a model that accurately simulates the spatial distribution of emissions and uses source strengths that are at least in qualitative agreement with accepted values. Our model meets these criteria so we can proceed with some sensitivity experiments. We pose the question of whether the proposed instruments will be able to detect a $50 \%$ reduction in surface emissions from Germany and the Netherlands (G\&N).

Figure 7 charts the approach. We start with the methane surface emissions retrieved from the surface observations from 1 July to 14 August (also shown in Fig. 5) and label them "truth" (black box in Fig. 7). A forward model (Fig. 2b) generates total column $\mathrm{CH}_{4}$ on a $1 \times 1^{\circ}$ grid. Although the proposed laser instruments will be able to measure total column cloud in between clouds, measurements under fully overcast conditions are not possible. For this study we use cloud optical depths observed by the CALIPSO instrument (Cloud-Aerosol Lidar and Infrared
Pathfinder Satellite Observations; Winker et al., 2009), since its satellite platform orbit will likely be similar to the one planned for the MERLIN instrument. The level 2 product, "CAL_LID_L2_05kmCLay", provides cloud optical depths for a $5 \mathrm{~km}$ field of view (FOV) along the satellite flight track. A total column $\mathrm{CH}_{4}$ from our forward model is spatially interpolated at each $5 \mathrm{~km}$ FOV. If the cloud optical depth is below 0.5 , the $5 \mathrm{~km} \mathrm{CH}_{4}$ amount is included in a $70 \mathrm{~km}$ average; $5 \mathrm{~km}$ FOV values with higher cloud optical depths are rejected. If all FOVs are clear, 15 adjacent $5 \mathrm{~km}$ values are included in the $70 \mathrm{~km}$ average. The result is a $\sim 8000$ element vector of total column $\mathrm{CH}_{4}$ averages. We consider two types of instruments: one assumes a very low noise level of $0.47 \mathrm{ppb}$ per $5 \mathrm{~km}$ FOV measurement and a second assumes noise levels consistent with the proposed instruments, $47 \mathrm{ppb}$. The results are vectors of simulated $\mathrm{CH}_{4}$ column amounts that the instrument would observe over a $20 \mathrm{~d}$ period. These are termed observables and are shown in Fig. 8. Separately, we input the simulated column $\mathrm{CH}_{4}$ observations to a flux retrieval algorithm similar to the one depicted in Fig. 3. As before, we use the standard linear inverse method (chapter 3 of Rodgers, 2000). For the first guess (a priori) we use a homogeneous field of very low source strengths, $0.5 \mathrm{mg} \mathrm{day}{ }^{-1} \mathrm{~m}^{-2}$. We set the uncertainty in the observations consistent with the added noise. We assume no spatial covariance so the off-diagonal elements of the forward model error covariance matrix are zero. The results are retrieved surface 

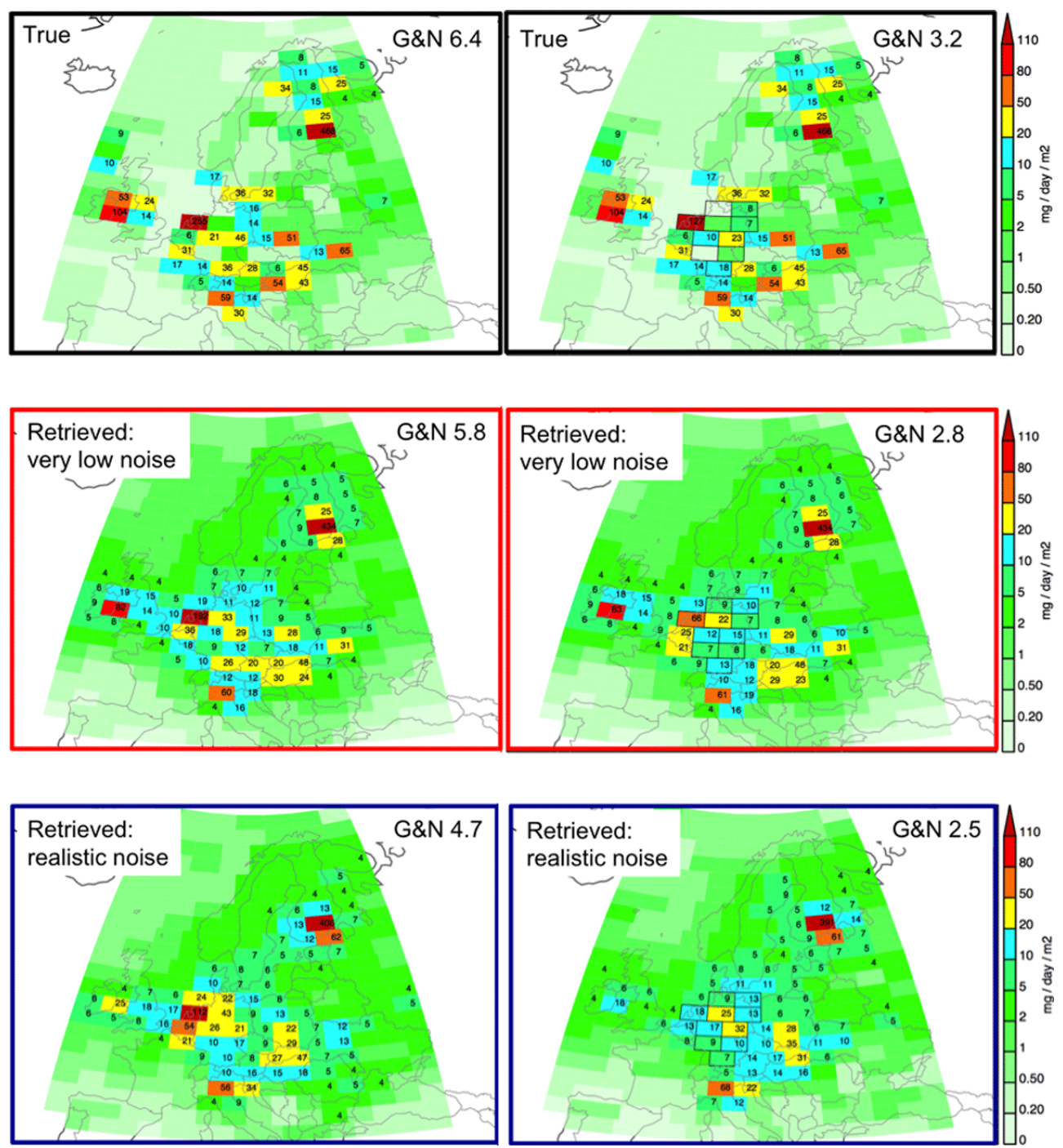

Fig. 9. Surface emission of $\mathrm{CH}_{4}$ from the sensitivity experiments outlined in Fig. 7. The three left-hand panels are from a control experiment that starts with our best estimate of the actual surface fluxes as shown in Fig. 5 for 1 July-14 August (recall these were inverted from data sampled at the 9 European $\mathrm{CH}_{4}$ monitoring stations). The color of the panel perimeter (black, red and blue) refers to the color of the boxes in Fig. 7. The value for G\&N (Germany and the Netherlands) is the cumulative emission for Germany and the Netherlands in tera-grams (Tg) per year. The three right-hand panels are for the perturbation experiment where the cumulative emissions for Germany and Netherlands is reduced by half.

$\mathrm{CH}_{4}$ emissions at the 262 grid boxes; they are shown in the black and red boxes of Fig. 7 .

We run two cases. The control case starts with our best estimate of the actual surface fluxes from 1 July to $14 \mathrm{Au}-$ gust. During this period the cumulative G\&N emissions are $6.4 \mathrm{Tg} \mathrm{yr}^{-1}$. The perturbation case reduces the G\&N emissions $50 \%$ to $3.2 \mathrm{Tg} \mathrm{yr}^{-1}$. The top panels of Fig. 9 are the "true" emissions used for these two cases. The grid boxes over G\&N are outlined in black on the right-hand panels. When we only account for biases from instrument sampling and rejection of $5 \mathrm{~km}$ FOV observations for cloud conditions, we retrieve surface fluxes shown in the middle (red panel outline). Here we assume a very low instrument noise level of $0.47 \mathrm{ppb}$ per $5 \mathrm{~km}$ FOV measurement. Despite the reduction in observed information due to data rejection for cloud conditions, the perturbation retrievals are still similar to the truth. The retrieved emissions over G\&N are 5.8/2.8 for the control/perturbation case, respectively. Also note that both cases maintain the strong emissions over Finland, Ireland and northern Italy, as they should. When the instrument noise is increased to the level expected for the proposed instruments, we retrieve the emissions shown at the bottom of Fig. 9 (blue outlined panels). As expected, there is further degradation from the truth but the retrieved emissions over G\&N are still lower for the perturbation vs. control case (2.5 vs. 4.7). We repeated this sensitivity experiment for a 20 day 
period in winter using retrieved fluxes from 15 November to 31 December. More persistent cloudy conditions during winter vs. summer result in retrieved fluxes that do not compare well with the truth, especially when realistic noise levels are assumed. Increasing the time duration of the observable to more than 20 days will improve the retrievals. Unfortunately, available computational resources precluded inversion of a larger matrix.

\section{Conclusion}

We have developed a simple forward model using the FLEXPART trajectory model to simulate ground-based in situ and spaceborne (total column) measurements from proposed $\mathrm{CH}_{4}$ lidar instruments. This forward model is used in conjunction with a retrieval algorithm to obtain estimates of surface emissions over Europe that are constrained by $3 \mathrm{~h}$ surface observations sampled at nine European ground stations. The model is generally able to simulate the daily variability in surface $\mathrm{CH}_{4}$ concentrations observed at the ground stations. This suggests the model correctly simulates the filaments that transport $\mathrm{CH}_{4}$ from their sources to the groundbased stations.

The model is then used to determine if the detection limits and measurement precision of the proposed instruments are low enough to detect significant changes in $\mathrm{CH}_{4}$ surface emissions. We have applied our model to a future scenario where the emissions from Germany and the Netherlands are reduced by $50 \%$. In summer, this perturbation can be detected to within $22 \%$ using 20 days of sampled column $\mathrm{CH}_{4}$ amounts using the error specifications of the proposed instruments.

Acknowledgements. This research was funded by Deutsches Zentrum für Luft- und Raumfahrt (DLR) and the NASA ASCENDS Flight Projects development. The authors thank the scientists, research technicians and graduate students that monitor the worldwide ground-based surface observational network that measure trace gases. We appreciate the patience and comments of the two anonymous reviewers.

Edited by: M. Heimann

\section{References}

Aalto, T., Hatakka, J., and Lallo, M.: Tropospheric methane in northern Finland: seasonal variations, transport patterns and correlations with other trace gases, Tellus, 59B, 251-259, 2007.

Abshire, J. B., Riris., H., Allan, G., Weaver, C. J., Mao, J., Sun, X., Hasselbrack, W. E., Kawa, R. S, and Biraud, S.: Pulsed airborne lidar measurements of atmospheric $\mathrm{CO}_{2}$ column absorption, Tellus, 62B, 770-783, 2010.

Abshire, J. B., Riris, H., Allan, G., Weaver, C. J., Mao, J., Sun, X., Hasselbrack, W. E., Kawa, R. S, and Biraud, S.: Airborne Measurements of $\mathrm{CO}_{2}$ Column Absorption and Range using a
Pulsed Direct-Detection IPDA Lidar, Appl. Opt., 52, 4446-4461, doi:10.1364/AO.52.004446, 2013.

Apadula, F., Gotti, A., Pigini, A., Longhetto, A., Rocchetti, F., Cassardo, C., Ferrarese, S., Forza, R.: Localization of source and sinks regions of carbon dioxide through the method of the synoptic air trajectory statistics, Atmos. Environ., 37, 3757-3770, 2003.

Bergamaschi, P., Frankenberg, C., Meirink, J. F., Krol, M., Villani, M. G., Houweling, S., Dentener, F., Dlugokencky, E. J., Miller, J. B., Gatti, L. V., Engel, A., and Levin, I.: Inverse modeling of global and regional $\mathrm{CH} 4$ emissions using SCIAMACHY satellite retrievals, J. Geophys. Res., 114, D22301, doi:10.1029/2009JD012287, 2009.

Bergamaschi, P., Frankenberg, C., Meirink, J. F., Krol, M., Dentener, F., Wagner, T., Platt, U., Kaplan, J. O., Körner, S., Heimann, M., Dlugokencky, E. J., and Goede, A.: Satellite chartography of atmospheric methane from SCIAMACHY on board Envisat: 2. Evaluation based on inverse model simulations, J. Geophys. Res., 112, D02304, doi:10.1029/2006JD007268., 2007.

Bergamaschi, P., Krol, M., Meirink, J. F., Dentener, F., Segers, A., van Aardenne, J., Monni, S., Vermeulen, A. T., Schmidt, M., Ramonet, M., Yver, C., Meinhardt, F., Nisbet, E. G., Fisher, R. E., O'Doherty, S., and Dlugokencky, E. J.: Inverse modeling of European $\mathrm{CH}^{4}$ emissions 2001-2006, J. Geophys. Res., 115, D22309, doi:10.1029/2010JD014180, 2010.

Delhotal, C. K., de la Chesnaye, F. C., Gardiner A., Bates, J., and Sankovski, A.: Mitigation of Methane and Nitrous Oxide Emissions from Waste, Energy and Industry, Ener. J., Special Issue No. 3, 45-62, doi:10.5547/ISSN0195-6574-EJ-VolSI2006NoSI3-3, 2006.

EDGAR European Commission, Joint Research Centre (JRC)/Netherlands Environmental Assessment Agency (PBL), Emission Database for Global Atmospheric Research (EDGAR), release version 4.2, available at: http://edgar.jrc.ec.europa.eu (last access: 2013), 2011.

Ehret, G., Fix, A., Kiemle, C., and Wirth, A.: Space-borne monitoring of methane by intergrated parth differential absorption lidar: Perspective of DLR's CHARM-SSB mission, Proc. 24th International Laser Radar Conference, 1208-1211, 2008.

Frankenberg, C., Aben, I., Bergamaschi, P., Dlugokencky, E. J., van Hees, R., Houweling, S., van der Meer, P., Snel, R., and Tol, P.: Global column-averaged methane mixing ratios from 2003 to 2009 as derived from SCIAMACHY: Trends and variability, J. Geophys. Res., 116, D04302, doi:10.1029/2010JD014849., 2011.

Kiemle, C., Quatrevalet, M., Ehret, G., Amediek, A., Fix, A., and Wirth, M.: Sensitivity studies for a space-based methane lidar mission, Atmos. Meas. Tech., 4, 2195-2211, doi:10.5194/amt-42195-2011, 2011.

Meirink, J. F., Bergamaschi, P., and Krol, M. C.: Fourdimensional variational data assimilation for inverse modelling of atmospheric methane emissions: method and comparison with synthesis inversion, Atmos. Chem. Phys., 8, 6341-6353, doi:10.5194/acp-8-6341-2008, 2008

Necki, J., Schmidt, M., Rozanski, K., Zimnoch, M., Korus, A., Lasa, J., Graul, R., and Levin, I.: Six-year record of atmospheric carbon dioxide and methane at a high-altitude mountain site in Poland, Tellus, 55B, 94-104, 2003. 
Paatero, J., Hatakka, J., and Viisanen, Y.: Meteorological aspects of radon-222 concentrations in the air at the Pallas GAW station, Northern Finland, J. Aerosol Sci., 30, Suppl. 1, S603-S604, 1999.

Reimann S., Vollmer, M. K., Folini, D., Steinbacher, M., Hill, M., Buchmann, B., Zander, R., and Mahieu, E.: Observations of Anthropogenic Halocarbons at the High-Alpine site of Jungfraujoch for assessment of trends and European sources, Sci. Total Environ., 391, 224-231, 2008.

Riris, H., Numata, K., Li, S., Wu, S., Ramanathan, A., Dawsey, M., Mao, J., Kawa, S. R., and Abshire, J. B.: Airborne measurements of atmospheric methane column abundance using a pulsed integrated-path differential absorption lidar, Appl. Optics, 51, 8296-8305, 2012.

Rodgers C.: Inverse methods for Atmospheric Soundings World Scientific, Inverse methods of Atmospheric Soundings, World Scientific, Singapore, 238 pp., 2000.

Schepers, D., Guerlet, S., Butz, A., Landgraf, J., Frankenberg C., Hasekamp O., Blavier, J.-F., Deutscher, N. M., Griffith, D. W. T., Hase, F., Kyro, E., Morino, I., Sherlock, V., Sussmann, R., and Aben I.: Methane retrievals from Greenhouse Gases Observing Satellite (GOSAT) shortwave infrared measurements: Performance comparison of proxy and physics retrieval algorithms. J. Geophys. Res., 117, D10307, doi:10.1029/2012JD017549., 2012.

Shindell, D., Kuylenstierna, J. C. I., Vignati, E., van Dingenen, R., Amann, M., Klimont, Z., Anenberg, S. C., Muller, N., JanssensMaenhout, G., Raes, F., Schwartz, J., Faluvegi, G., Pozzoli, L., Kupiainen, K., Höglund-Isaksson, L., Emberson, L., Streets, D., Ramanathan, V., Hicks, K., Oanh, N. T. K., Milly, G., Williams, M., Demkine, V., and Fowler, D.: Simultaneously mitigating near-term climate change and improving human health and food security, Science, 335, 183-189, doi:10.1126/science.1210026, 2012.
Stephan, C., Alpers, M., Millet, B., Ehret, G., Flamant P., Deniel, C.: MERLIN: a space- based methane monitor, Lidar Remote Sensing for Environmental Monitoring XII, Proc. SPIE, 8159, 815908, 2011.

Stohl, A., Forster, C., Frank, A., Seibert, P., and Wotawa, G.: Technical note: The Lagrangian particle dispersion model FLEXPART version 6.2, Atmos. Chem. Phys., 5, 2461-2474, doi:10.5194/acp-5-2461-2005, 2005.

Vermeulen, A. T., Pieterse, G., Hensen, A., van den Bulk, W. C. M., and Erisman, J. W.: COMET: a Lagrangian transport model for greenhouse gas emission estimation - forward model technique and performance for methane, Atmos. Chem. Phys. Discuss., 6, 8727-8779, doi:10.5194/acpd-6-8727-2006, 2006.

Winker, D. M., J. Pelon, J. A. Coakley Jr., S. A. Ackerman, R. J. Charlson, P. R. Colarco, P. Flamant, Q. Fu, R. M. Hoff, C. Kittaka, T. L. Kubar, H. Le Treut, M. P. Mccormick, G. Meìgie, L. Poole, K. Powell, C. Trepte, M. A. Vaughan, and B. A. Wielicki: The CALIPSO Mission. A Global 3D View of Aerosols and Clouds. Bull. Am. Meteorol. Soc., 1211-1229, DOI:10.1175/2010BAMS3009.1, 2010. 


\section{Appendix A}

The Pallas-Sammaltunturi station $(560 \mathrm{~m})$ is located within the northern boreal forest zone and is free of large local and regional pollution sources (Aalto et al., 2006). Analysis of radon-222 concentrations indicates that the station is very rarely inside the surface inversion layer (Paatero et al., 1999). This is consistent with its location atop a $560 \mathrm{~m}$ hill.

The Schauinsland monitoring station $(1205 \mathrm{~m})$ is situated on a mountain ridge in the Black Forest, southwest Germany, above the polluted Rhine Valley. During nighttime the station is usually above the boundary layer, while during daytime, particularly in summer, the Schauinsland station mostly lies within the convective boundary layer.

The Neuglobsow sampling site $(65 \mathrm{~m})$ is surrounded by lakes and forested areas in all directions, and therefore only very slightly influenced by local sources. Measurements here can be taken as representative for the background in northeastern Germany.

The Jungfraujoch station $(3580 \mathrm{~m})$ is a high alpine station located in the center of Western Europe. During extended periods, the Jungfraujoch is decoupled from the tropospheric boundary layer below. On the other hand, transport of polluted boundary layer air to the height of the Jungfraujoch occurs periodically because of meteorological transport connected with the passage of fronts, foehn winds, or thermally driven convection during anticyclonic periods in summer (e.g., Reimann et al., 2008).
The Kasprowy Wierch station $(1989 \mathrm{~m})$ is located on a peak in the Tatra Mountains, vertically situated within the transition zone between the free troposphere and the boundary layer (Necki et al., 2003).

The Mace Head station $(5 \mathrm{~m})$ is located on the west coast of Ireland, offering westerly exposure to the North Atlantic Ocean (clean sector, $180^{\circ}$ through west to $300^{\circ}$ ) and the opportunity to study atmospheric composition under Northern Hemispheric background conditions as well as European continental emissions. The meteorological records show that on average, over $60 \%$ of the air masses arrive at the station via the clean sector. These air masses are ideal for carrying out background aerosol and trace gas measurements. Significant pollution events also occur at the site when European continental air masses, generally originating from an easterly direction, reach Mace Head.

The Kollumerwaald station $(0 \mathrm{~m})$ is located in a coastal agricultural area in the province Friesland, the Netherlands.

The Monte Cimone station $(2165 \mathrm{~m})$ is situated in the Italian northern Alpennines. There are no local sources of contamination and no access by road.

The Plateau Rosa (3480 m) station is situated in the western Italian Alps. Due to its high altitude and location, i.e., in the free atmosphere upon a large snow-clad bare mountain plateau and far from urban and polluted zones, it is suitable for the background measurements of greenhouse gases. 